\title{
A Methodology for Field-testing Concepts Through Expert Practitioner Engagement
}

Peter Howie \& Richard Bagnall

\begin{abstract}
This paper presents a methodology for field-testing concepts through practitioner engagement. It was developed and trialled in a study involving the critique and reconceptualisation of the psychodramatic concept of warm-up. A critical review of the concept led to a reconceptualisation and description from which an explanatory document was drawn together as the lead statement for surveying psychodrama practitioners. The field-testing used online software to communicate with selected international participants. The lead document and survey invited critical text-based evaluative responses to the reconceptualisation. The responses were processed by selecting those with substantive critical comment and then clustering them according to a framework of criteria designed for concept evaluation. Responses were reviewed critically in the context of the overall conceptualisation and incorporated as appropriate into it. The process provided significant support for the new conceptualisation as well as critical input that led to its further improvement.
\end{abstract}

Keywords: concept testing; concept evaluation; re-conceptualizing; field-testing concepts.

\section{Introduction}

Methodologies for the field-testing of concepts, whether newly created concepts or reconceptualisations from existing ideas, are scant. While the development, creation, and construction of new concepts is well catered for in the scholarly literature, as is indicated in the large number of well-cited research and methodological texts available, there is negligible scholarly theorising on their evaluative field testing. Such a lack may arguably contribute to inadequate concept clarity (Locke, 2012). This paper seeks to clarify what 
field-testing a new or existing concept might amount to and to advance a methodology for doing so.

The methodology was developed to test a reconceptualisation of the concept of warm-up as is has been used in the field of psychodrama. The imperative for such a reconceptualisation was identified from a critical review of literature engaging with the concept in that context. The review found the concept to be inadequate to the demands of the context, calling for the concept's refinement or reconceptualisation. The critical review was then used as the basis for developing a reconceptualisation of the concept, which was then field-tested through a methodology developed for the purpose. The methodology sought to use e-technology to engage psychodrama practitioners in critically evaluating articulations of the reconceptualisation from their individual professional and scholarly perspectives. Open text-based responses from the test participants were analysed through a framework of criteria developed for the purpose. The findings of the field-testing provided not only for an evaluation and further refinement of the reconceptualisation, but also for an empirical testing of the of the field-testing methodology, which latter is here described.

That description begins here with an explication of the meaning of the term concept as it is used here, with comments on the idea of conceptual adequacy. It then briefly considers the issue of the lack of conceptual clarity and consistency, and some of the ways in which attempts have been made to bring order to what at times may be seen to be an unruly mess. Clarification of the notion of the field-testing of concepts follows. The methodology used to field-test the reconceptualisation is then presented as a case study through explaining: the background of the research project, the process of reconceptualisation, the development of an explanatory document for the field-testing, participant selection, respondent contact, development of the survey instrument, the online software used, response rates and responses, processing the responses, and refining the initial concept. The paper concludes with a reflective consideration of the value of such field-testing as a methodology for concept refinement.

\section{The Idea of a Concept}

In this paper, the notion of a concept is that which is encompassed by a descriptive term. It thus identifies the scope of the concept signified by that term. That which is encompassed by a descriptive term is also understood as its denotation or referent and is standardly 
represented by a description of its scope, which is commonly referred to as a definition, or the connotation, or meaning of the term (Salmon, 1984; Sartori, 1984). Such a description will inevitably use further concepts to elucidate the properties or qualities of the concept, including classes of objects, phenomena, or situations covered by it. In the present study, the descriptive term is that of warm-up.

The meaning of any descriptive term - the scope of the concept encompassed by that term - will standardly vary across the cultural contexts of its use, so that any one definition of a descriptive term will normally be suitable for use only within a given cultural context (or a cluster of cognate cultural contexts). For example, the descriptive term 'scholarly journal' in an academic context has as its scope (denotation or referent) all those publications that may be considered to be both scholarly and of the nature of a journal. A definition of that term (its meaning or connotation) - a description of its scope - in that context will be along the lines of 'any serialised publication that purports to publish work grounded in one or more formal disciplines of inquiry'. The idea of re-conceptualizing a concept, then, involves reviewing the ways in which the descriptive term identifying a concept (scholarly journals in this case) is defined, either explicitly, in the definitions used to describe its meaning, or implicitly, in the referents to which it has been ascribed within pertinent cultural contexts (academic discourse in this case).

For example, the work of Hatfield and Polomano (2012) involved the reconceputalisation of the concept of infant distress in the context of nursing practice and scholarship. The authors found that the concept in that context was unclear, with nurses being unable to distinguish clearly different forms of infant distress from infant pain, leading to a general inability to identify appropriate pain management interventions for infants. Their analysis began the process of re-conceptualizing the concept by considering the term's use in the nursing context: the essential features of the concept, its antecedents, and its consequences. They then used that analysis to improve the usefulness of the concept to nurses in correctly identifying infant distress responses to pain, as distinct from distress not involving pain: thereby enhancing the concept's utility in nursing research and practice.

\section{Conceptual Adequacy}

Conceptual adequacy is a formal notion identifying the extent to which a concept is fitted to a particular task (Gerring, 1999). It is therefore contextualised to that task. In the present 
study, the context is that of the practice and discipline of psychodrama. The fittedness of the concept of warm-up to that field, then, may be understood as the extent to which the concept facilitates not only psychodramatic practice, but also the generation of knowledge about that practice, and the communication and application of that knowledge to inform further practice.

An extensive and thorough critical review of literature referring to warm-up in psychodrama (Howie \& Bagnall, 2015) identified a confusion of different and over-lapping conceptions of warm-up in psychodrama, a common lack of clarity about the term's meaning intended on any particular occasion, and hence a general lack of fittedness to the field. The review identified four different, but commonly confused and little understood concepts of warm-up in the field. One of these concepts - the individual warm-up state has been argued to be foundational to the others and the least conceptualised, and was therefore selected as the focus of a reconceptualisation.

The reconceptualisation was considered to require the use of a formal framework through which the decisions taken could be made transparent and open to evaluation by other users. Formal frameworks for assessing conceptual adequacy and for developing and testing conceptual refinements - such as those of Sartori (1984) for political science concepts, Gerring $(1999,2012)$ for social science concepts, and Meleis (2012) for concepts specific to nursing, were critically reviewed and evaluated for the task. None, though, was judged to be sufficiently clear, unambiguous, and appropriate to the task at hand. Accordingly, a refined framework of eight criteria in three categories was developed for the project from the critical review: ${ }^{1}(1)$ the intrinsic qualities of a concept (its clarity, comprehensiveness, parsimony, and resonance); (2) its contextualisation (differentiation, and connectedness), and (3) its application (epistemic utility, and practical utility).

That framework, then, was used to develop the reconceptualisation (the redescription) of the concept of the individual warm-up state. The reconceptualisation, though, presented a need for its evaluative field-testing with psychodrama practitioners, both to obtain information on its adequacy to their purposes, and to identify any ways in

\footnotetext{
${ }^{1}$ The framework of criteria drew primarily on the works of Bacharach $(1989)$, Blalock $(1969,1982)$, Blumer (1931, 1954), Dubin (1978), Fawcett (1995), Gerring (1999, 2012), Glaser (2002), (Kuhn, 1977), Meleis (2012), Patterson (1986), Prochaska, Wright, and Velicer (2008), Proctor and Capaldi (2006), Sartori (1984), and Wilson (1969).
} 
which it might be improved, before advancing it openly for adoption. It is the approach developed for and taken in that field-testing that is here described and reflected upon, in the hope that it may be of value in informing similar endeavours with other concepts.

\section{Field-testing the Reconceptualisation}

Traditional approaches to field-testing concepts have focused on attempts to use consultative processes, such as participatory action research, which seek opinions and feedback from a variety of concept users, usually to determine the state of play in a particular context and to bring a form of creative consensus to bear through dialogue (Carter, 2002; Kezar \& Maxey, 2014). Action research in this context is a problem-driven approach, with a real-world issue being the motivation for enquiry. Similarly, co-operative inquiry, expert inquiry, and practitioner inquiry align with something akin to developing a 'best practice' for solving a problem (Heron \& Reason, 2006). The Delphi methodology more specifically has been used to develop a common stance through a process of convergent questioning of experts, practitioners, or users (Shelton \& Creghan, 2014; Skulmoski, Hartman, \& Krahn, 2007). These approaches all focus, in one way or another, on achieving consensual convergence on definitional features of initial divergence. As such, they may be seen as socio-psychological ploys for attaining popular agreement on points of difference within the common range of conceptual understanding. Such approaches were seen as inappropriate and inadequate for the present task, where a reconceptualisation developed from a systematic analysis of conceptual usage was already available for critical assessment. Consensual convergence on such a reconceptualisation would obscure points of difference or concern and ways in which the reconceptualisation might better encompass particular ideas.

Field-testing a thoroughgoing reconceptualisation called, rather, for a process that would: (1) encompass a wide diversity of individuals in different practitioner and scholarly roles and cultural contexts - both internationally and locally - in psychodrama; (2) give each of those individuals the opportunity to articulate, in as much detail as they chose, their assessment of the reconceptualisation; (3) give each respondent the opportunity to explain the ways in which the reconceptualisation may be improved for their particular purposes; and (4) make all that information available to the researchers for consideration and inclusion in the refinement of the reconceptualisation. The methodology developed with 
these parameters in mind, sought also to optimise the use of contemporary computer technology to facilitate any or all phases of the process.

\section{Developing the Explanatory Test Document}

A short (242-word) explanatory document of the reconceptualisation was drawn together as the lead statement for field-testing. A more comprehensive (938-word) statement was also fleshed out into as comprehensive an explanation as was practicable, to increase the likelihood of the concept being recognisable to the psychodrama professional audience at large. A comprehensive variety of connotative and denotative elements were included in the latter statement. It was assumed that, while all survey respondents would be interested in the outcomes of the survey, there would nevertheless be variation amongst respondents as to whether the shorter or the longer version of the articulation of the concept would be preferred. Both explanatory documents had web-based links to the review by Howie and Bagnall (2015), which clarified the four concepts of warm-up extant in the milieu of psychodrama.

\section{Selecting the Communication Media, the Protocol and the Approach}

The survey instrument was developed using Limesurvey software, available through the host university, though similar proprietary software, such as Google Drive-Forms, Survey Monkey, Smart Survey, or DataField, may have provided similar functionality. Limesurvey permitted respondents to revisit the survey and to modify or add to their previously entered responses, while the data remained secure on the researcher's university server. This type of process was favoured because it provided the opportunity for more considered responses than those that might be more affected by the propinquity of initial responses. The survey instrument also permitted the use of different media, including concept demonstration video clips and explanatory text material, which were further provided. Other strengths of the survey instrument were its capacity to: permit targeted responder participant sets; have responder sets entered in bulk through comma-delimited text files (such as may be exported from Excel and other databases or spreadsheets); have optional levels of anonymity (from being known to the researcher through to being invisible to the researcher); provide real time response access by the researcher; allow immediate 
modification of the survey when errors were reported by respondents; permit automated emailing, both of the initial invitation and the subsequent follow-up reminders, to those who had not responded; allow an automatic opt-out option for participants; permit comments at all stages of the survey; allow for the capture of a variety of research data, in addition to the text responses of respondent; include the engagement time of the respondents; and allow for the downloading of text and related material in a wide variety of formats, directly into Excel spreadsheets or Word-type programs.

\section{Selecting Participants}

The participants selected for the field-testing were qualified psychodrama practitioners from professional psychodrama organisations, both locally and internationally. The bulk of them were chosen because (a) they had prior professional contact with the researcher, as it was thought probable that such contact would improve the likelihood of their responding, and (b) they were known by the researcher to have both a strong knowledge of psychodrama and extensive experience with it. In total, 374 psychodrama practitioners were thus selected and sent an invitation to participate: 111 in Australia or New Zealand, 141 in the USA or Asia, and 122 in Europe.

Prior to the selected participants being contacted, the impending survey was publicised through the Australian and Aotearoa New Zealand Psychodrama Association channels, conference papers, and via an email forum, to alert practitioners to the possibility of their being invited to participate in the research, and inviting them to consider their involvement in advance. Respondents were then directly contacted on up to three occasions, as needed, to encourage them to respond. Approximately four weeks after the initial publicity, the first direct contact email alert was sent, advising of an invitation to participate that would be following shortly, arguing succinctly for the value of their participation, but also inviting them to deselect themselves from further contact if that was their preference. The invitation letter was pitched to encourage their cooperation in order to progress the theory of psychodrama. Two invitees withdrew at that stage, citing health reasons. Approximately two weeks later, an invitation was sent directly to the remaining 372 potential participants. The invitation included web-based links to the short and longer articulations, as well as the article by Howie and Bagnall (2015), which explained the four concepts of warm-up extant in the milieu of psychodrama. The invitation included an 
automatically generated email link unique to each respondent, giving individualised access to the online survey and a one-month opportunity to respond from the date of sending the email. Also included in the online survey were six video clips prepared as a form of concept grounding to alert respondents to the specifics of the reconceptualisation, and an explanatory framework for the work being done. Respondents thus had the opportunity to engage with the reconceptualisation in different forms and to different depths. A second email was sent if participants had not responded prior to the survey ending date. Upon receipt of each response, the respondent was individually thanked, with the researcher making short, specific responses to any queries or questions.

\section{The Survey Instrument}

The survey was designed to open with a very similar invitation to the one that was emailed out to respondents. It was assumed that potential respondents may not have carefully read the invitation or even checked out the online survey when they first received the invitation. Hence, the opening page in the online survey again stated the objectives of the survey and invited their response, which in this case meant continuing to the next phase of the survey. Immediately following this welcome in the survey, respondents were invited to supply background information through the following questions:

(1) How long have you been practicing, or have you practiced, as a psychodramatist, sociodramatist, sociometrist or role trainer?

(2) What is your qualification with regards to psychodrama?

(3) In which country did you qualify or with which professional association did you qualify?

(4) Does your practice involve groups?

(5) In what percentage of your time in your practice do you work with groups?

(6) How, if at all, do you use the concept of warm-up in your work or life?

The questions were intended to assist in interpreting and evaluating the usefulness of each respondent's critique of the concept. The first question was designed to situate the respondent in their career as a professional user of the concept being field-tested. It allowed them to specify the form of professional practice in which they worked: psychodrama, sociodrama, sociometry, or role training, each of which is a form of 
psychodrama practice. The second question invited them to specify their professional qualification. Both these questions assisted in evaluating the significance of individual responses. The third question was designed to assist in explaining any variation in responses associated with differences in the theoretical stances of professional associations. The fourth and fifth questions were designed to assist in interpretating response variations associated with respondent levels of work time in group settings. The final question was designed to allow respondents to reject the premise that they used the concept being fieldtested. It also permitted respondents to specify, if they so chose, how they worked with the concept of warm-up.

Although the survey was designed for experienced psychodrama practitioners, it was assumed that the majority would not have seen the new conceptualisation prior to its presentation in the survey. Accordingly, following the welcome message at the beginning of the survey, there was presented a succinct articulation of the background to the research project and a reminder of the history of the warm-up concept. Then followed the short and long forms of the concept developed earlier. Space was left for respondents to make comment at that point if they so chose.

It had been argued elsewhere that psychodrama practitioners are a pragmatic and practical group of practitioners exhibiting a tendency to underutilise writing, theorising, and conceptual frameworks in favour of active engagement (Howie, 2012). In recognition of that tendency, some short video clips that might be seen as demonstrative of the concept of the individual warm-up state were also provided. The first two of these were short movie clips. One was a 72-second clip from The King's Speech, where the King is seen to be swearing loudly. It was presented as an example of the concept of an individual warm-up state. Another included two 52-second consecutive clips from One Flew Over the Cuckoo's Nest, showing a young man gaining and then losing his confidence in a very dramatic fashion. It was presented as another example of an individual warm-up state. These clips had short explanatory passages on either side of them, which also asked the question of whether or not they could be seen as suggesting that movie directors might be familiar with the concept of the individual warm-up state. The remaining three videos were 59-, 60-, and 139second clips of psychodramatic enactments displaying evidence of the concept under consideration. These three videos were prepared following ethical clearance from the University. The participants in the videos were experienced psychodrama aficionados who 
volunteered to be filmed while engaging in demonstrating the concept of warm-up as part of the research project. They all gave consent to be filmed. The material filmed was of a social rather than a therapeutic nature, and it avoided any content of an overly personal or deeply confidential nature. All the video clips were embedded in the online survey. The survey structure had space for respondents to add reflections alongside each video clip.

Following the videos there was a short series of five questions about the reconceptualisation (Table 1), designed to encourage a high degree of responsiveness from respondents. The first of these questions invited respondents to score the reconceptualisation on a 10-point scale. The following three questions invited identification of the values used in that scoring and what the respondents most and least liked about the reconceptualisation. The final question invited recommendations on improving the reconceptualisation. Thus, the questions were open and the response area was a large freeform space in which they could write directly, or into which they could cut and paste if they so chose. This format allowed critical text-based evaluation of the reconceptualisation.

The survey finished with a short series of questions inquiring about the level of acknowledgement and citation that the respondent would prefer and permit, were their material to be used in any publication.

Table 1: The survey questions following the videos

\begin{tabular}{|c|l|}
\hline 1 & $\begin{array}{l}\text { Having read the presentation of the concept of warm-up, and viewed the video } \\
\text { clips, please rate this conceptualisation (notion, idea, or understanding) of the } \\
\text { concept of warm-up out of 10. (With } 0 \text { being inadequate, } 5 \text { being OK or just } \\
\text { adequate, and } 10 \text { being excellent.) }\end{array}$ \\
\hline 2 & $\begin{array}{l}\text { The previous question allows you a lot of room for interpretation and responding } \\
\text { from what you recognise, know, believe, and practice. In order for us to make } \\
\text { sense of your score please write about what values or criteria you are using in } \\
\text { coming to this rating. }\end{array}$ \\
\hline 3 & What do you like most about it? \\
\hline 4 & What do you like least about it? \\
\hline
\end{tabular}




\begin{tabular}{|c|l|}
\hline 5 & $\begin{array}{l}\text { What recommendations would you make to improve it? Please allow yourself } \\
\text { room to be specific or general, to recommend the adding of specific text or the } \\
\text { removal of specific text, remembering that the purpose of this research is to } \\
\text { improve the presentation of psychodrama theory. You are welcome to provide } \\
\text { recommendations of future questions, and future directions for research. You are } \\
\text { also welcome to both ask your own questions and answer them here. }\end{array}$ \\
\hline
\end{tabular}

Responses

The 372 survey questionnaires sent out produced a response rate of 26 per cent ${ }^{2}$ (96 respondents) and a completion rate of 79 per cent $^{3}$ (76 responses). Completed responses were an average of 351 words in length, respondent engagement with the survey averaging 64 minutes. However, the questionnaire did not segregate the number of times a person added to their questionnaire response; nor was it possible to ascertain whether participants actively engaged with the questionnaire or simply had it open while engaged in other activities. Respondents with incomplete responses supplied some demographic data and, while they did not answer the substantive questions, they nevertheless spent an average of nine minutes engaged with the process. The respondents had an average of 25 years of experience as psychodrama practitioners and were all highly qualified professionals in psychodrama. The response rate compares acceptably with Penwarden's (2014) suggested 24.8 per cent average response rate for a web-based survey. The quality of the experience of respondents, the length of time engaged with the field test, and the quantity of the critical text-based material returned suggested that the field test had at least returned significant informed and considered feedback on the acceptability of the reconceptualisation.

\section{Analysing the Responses}

The responses were initially examined to identify any substantively critical responses. Analysis then proceeded along two dimensions, the first being the extent to which the respondent recognised and supported the concept. This was done because it was not clear,

\footnotetext{
${ }^{2}$ Response rate was calculated by dividing the number of questionnaires sent out by the number of responses received.

3 The completion rate was calculated by dividing the number of responses received by the number in which respondents completed one or more of the open questions.
} 
prior to the field-testing, whether the concept was in general use, and whether that general use was congruent with the theorising undertaken by the researcher. While there was not a survey question that addressed this point directly, it became clear from responses whether or not it was the case. For instance, the initial question asking for concept usage in the respondent's work or life allowed for immediate rejection of the concept. The invitation to reflect on the concept following the watching of the video clips was another source of data permitting discrimination as to whether or not they supported the concept. Seventy-four practitioners largely accepted the concept and two largely rejected it. However, many respondents both accepted elements and rejected others. Overall there were 91 statements that indicated the value of the concept and the explication provided. There were 14 statements that rejected the concept or the explication, and 6 statements that expanded the concept into other areas of scholarly endeavour not previously considered pertinent by the researcher.

The second analytical dimension employed the eight criteria of conceptual adequacy drawn from the critical literature review as a heuristic to cluster the substantive statements in the responses. This analysis identified the distribution of the responses received across the criteria and allowed variations, agreements and disagreements amongst respondents to be considered easily as they were juxtaposed with comments addressing the same criterion.

Suggestions for refinement, along with conceptual and practice-based reflections, were then reviewed critically in the context of the overall conceptualisation and incorporated as appropriate into the next iteration of the reconceptualisation. Responses were also scrutinised for and aggregated on the basis of their evaluation of the reconceptualisation, those statistics being used in its final explanation. Although a wide range of comments and suggestions were made in the responses, as a set, they contributed significantly to the refinement of the reconceptualisation.

Responses to the questionnaire were categorised according to which conceptual criteria they could be said to address. These responses were then scrutinised as a group and boiled down to the essential questions they were raising, responses to which are considered in the next chapter that deals with reconceptualisation and developing a final definition of the concept. There are ways of viewing the criteria, such as the criteria of clarity, whereby the responses may be seen from a technical point of view (Is the concept accurate?) as well as from a presentational point of view (is it well written and are the visuals clear?). Thus, for 
example, a presentational discussion on the efficacy of the video material was considered relating to clarity and was grouped with broader discussions regarding clarity of the concept, as were recommendations that directly addressed clarity or one or other element of cohesiveness, intelligibility, comprehensibility or ambiguity.

\section{Criteria Used by Experienced Psychodrama Respondents}

The questionnaire asked open questions and was itself open-ended and left the focus of respondent's critique up to the respondent (Libarkin \& Kurdziel, 2002). As they were asked to rate the concept out of 10 without any individual criterion being mentioned, this was then followed by an invitation: In order for us to make sense of your score please write about what values or criteria you are using in coming to this rating. There were a wide variety of responses here, many of which were highly discursive and did not answer the question directly. For instance, one respondent gave the definition a rating of 10 and, additionally, responded to this question with:

Value: that we are all becoming, or in process, developing or emerging..... in the moment, the next moment.... and so on. Your conceptualisation acknowledges the fluidity or flow of human behaviour moment by moment, and the effects of multiple factors/influences on behaviour/a particular warm up. (Marks, L)

And another who gave a rating of 4 wrote:

I loved your 12 points of noticing, but your definition of warm up was overcomprehensive to my way of thinking. ${ }^{4}$

Such responses required careful consideration which, along with the various opportunities respondents had for commenting as they went through the questionnaire, showed that the responses could be interpreted in a number of ways. As a means of ordering the various responses the conceptual criteria developed for the criterial framework in the previous chapter provided a ready-made taxonomy. Thus, the framework was used as a means to order the responses according to the criteria to which they addressed themselves. The

\footnotetext{
${ }^{4}$ Respondents were invited to indicate if they wanted to be cited if their responses were used. Only those who agreed to be cited have had their names attached to direct quotations.
} 
responses more generally were either: critical responses to the written and visual material presented, professional or theoretical reactions to the material, or recommendations to improve or augment the material.

The following figure, Figure 6.6, indicates the approximate distribution of responses categorised according to the criterial framework. Many comments were capable of being categorised in more than one criterion, and were, and many individual responses addressed multiple criteria.

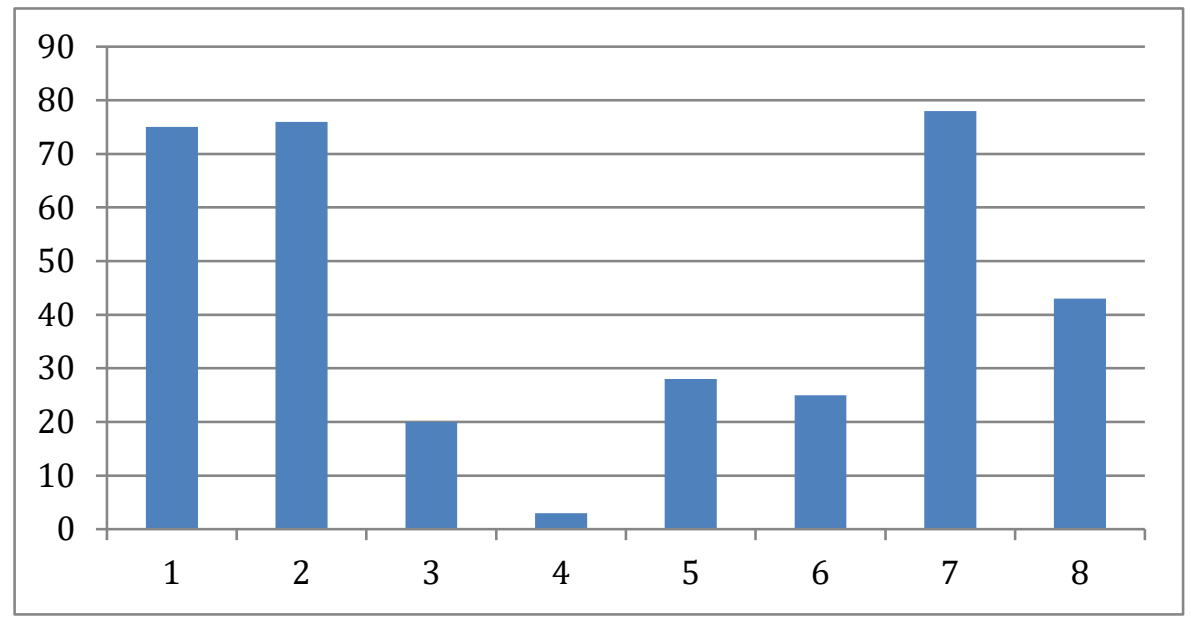

Figure 6.6 Psychodramatists' responses related to the 8 criteria. Key: Shaded line- number of responses (y-axis) relating to criteria (x-axis)

\section{Criteria Used by Non-psychodrama Respondents}

As mentioned earlier the questionnaire left the focus of any critique up to the respondent. There were a wide variety of responses, some discursive, many simply related to whether or not they liked the idea, or their struggle to understand an unfamiliar idea. For instance:

I'm still trying to understand exactly what it is - I think that I do grasp it. My uncertainty is how exactly this could be of any value in therapeutic work without much elaboration of the concept in the first place. (Anon).

As with the psychodramatist's responses, these responses fell within one or a number of the criteria developed for the criterial framework. For instance, the quote above addressed itself to the criterion of clarity and practical utility. Figure 6.10, following, indicates the distribution of responses according to the conceptual criteria of the criterial framework. 


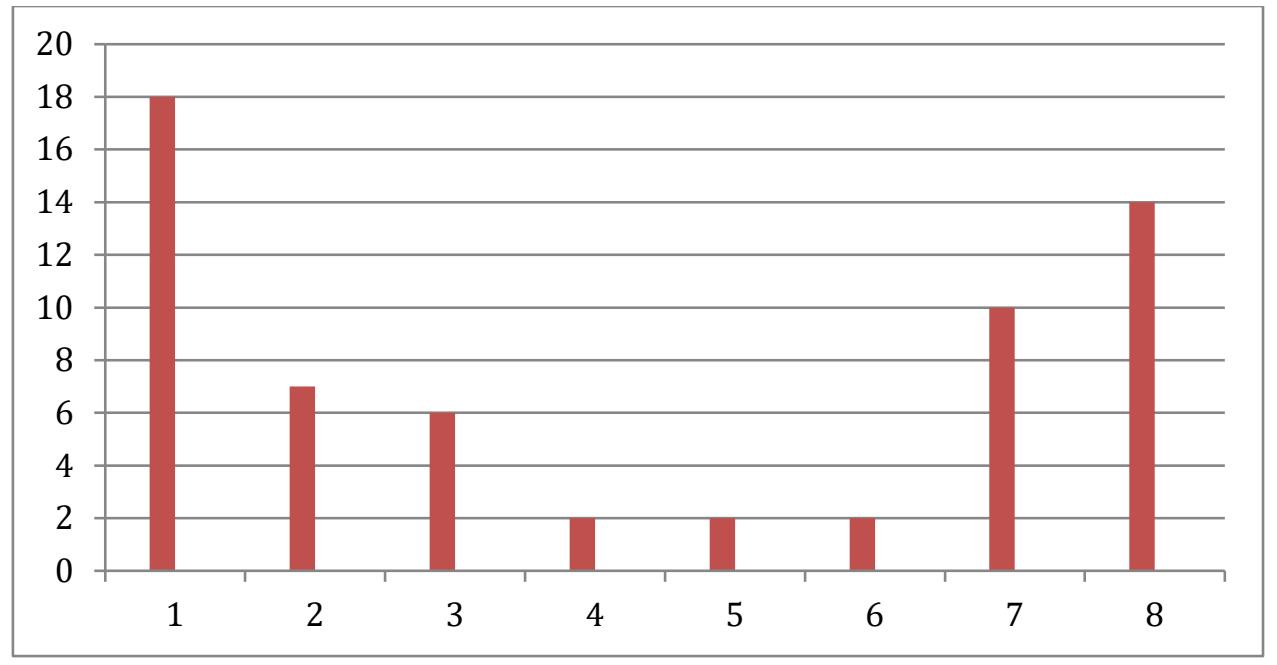

Figure 6.10 - Non-psychodramatists' responses related to the 8 criteria. Key: Shaded line- number of responses (y-axis) the criteria 1-8 (x-axis)

The responses focused more on the understandability criterion than did the responses from the psychodramatists. This makes sense when it is considered that people reading about a new concept are more likely to be struggling with understanding. It appears from the responses that the non-psychodramatists were able to make sense of the concept of warmup, and engage in a critical stance that made their responses useful for working with the conceptualisation.

\section{Discussion and Conclusions}

The methodology here described for field-testing a concept took the form of designing and disseminating a succinct explication of a concept as part of a survey to gauge the critical responses of individuals using the concept in their professional practice. The explication was embedded in a larger explanatory framework that argued for the importance of the concept testing with which they were being invited to engage, along with the provision of a variety of forms for reviewing it, including text and video. The survey was designed to permit respondents to critique the explication of the concept in a variety of ways through the use of open-ended online questions. Respondents were chosen as those best suited to either using or theorising the concept. This led to 26,676 words of critical text responses. Those data were scrutinised using a criterial framework designed for evaluating the adequacy of a concept. That framework permitted different but overlapping conceptual expressions from respondents to be considered contiguously. The responses provided the means for 
undertaking a thorough practitioner- and industry-situated re-evaluation and refinement of the description of the concept.

The case study of the methodology presented here involved a critical review and analysis of the literature of the concept of warm-up as its first step, which subsequently led to four new conceptualisations of the warm-up concept, three of which, it was determined, were to a large degree dependent on the fourth. The fourth, being both central to the conceptual cluster and the least well defined in the literature, was selected for field-testing. Field-testing was considered important as the practitioner field using the concept had not considered it as four interlocking and mutually dependent concepts with one of the four the individual warm-up state - being foundational to the others. The field-testing required the development of a succinct and a comprehensive statement of the concept, based on its use in the literature. This took into account the relative novelty of the description to the respondents. The valuing of the concept's explication was considered likely, thus potential respondents in professional channels and with connections to the researcher were alerted to the survey and then invited to engage with it. The respondents reviewed the material and gave wide-ranging feedback regarding its value to them and the usefulness and otherwise of the concept's description. This has permitted the first comprehensive evaluation of the concept of warm-up in psychodrama, as well as a professional review of the description of the individual warm-up state.

The case used to illustrate the methodology had a number of strengths. Firstly, the concept itself was well known though not well conceptualised in the scholarly literature. Thus the first step of undertaking a critical analysis and review of the literature was, in this case, a relatively straightforward proposition. Secondly, because of the choice of the concept and its context, eliciting thoughtful and critical responses was facilitated by the high level of interest. Thirdly, the concept's explication was able to be developed and understood without respondents being intimately familiar with all the various terms that different associations, cultures, and practice groups tend to build up around their otherwise similar work. The example chosen here allowed for a relatively plain-English description to be generated and used in the field-testing. The concept chosen allowed for different media to be used in representing it to respondents, in this case video as well as text, and this allowed for arguably better scrutiny of the concept than text alone would have allowed. Other concepts may not lend themselves so readily to such visual explication. 
The weaknesses in choosing this case to illustrate the methodology were, firstly, that the concept itself was relatively simple. A more complex concept and explication may have produced quantitatively and qualitatively different results to those obtained here, leading to further critical reflection on the methodology itself. Secondly, it may be necessary when using this methodology to choose concepts that are likely to elicit a positive response amongst practitioners in the field. That constraint may, in itself, limit the concepts that may feasibly be field-tested with the methodology. Thirdly, the use of the plain-English descriptions means that the methodology has not been tested with more complex disciplinary-focused concepts or those that involve other forms of argument, such as mathematics or physics. Fourthly, because the concept of warm-up was not well explicated in the literature prior to this undertaking, considerably more work was required to do this than may be required for better theorised and explicated concepts.

The strengths of the methodology, though, are that it allows for: (1) a conceptualisation for a particular task to be assessed by the practitioners who use it; (2) that assessment to be undertaken before the conceptualisation is formally published and widely disseminated; (3) the conceptualisation to be further refined to better serve the particular task, prior to its formal articulation; (4) variability in the depth of responses optimising the contribution from each respondent; (5) a large number of practitioners to be involved in the field-testing, across boundaries of practice and geography; (6) respondents to refine, add to, or delete from their responses as they engage; (7) the researcher to follow up with any respondent to seek clarification or further detail on any aspect of their response; (8) respondents both to contribute assessments of the value of the conceptualisation or any aspects of it and to provide suggestions for its improvement, to any level of detail; and (9) respondent practitioners to contribute significantly to the final conceptualisation.

The weaknesses of the methodology, then, relate to the amount of subsequent work that may be generated from inviting experienced practitioners to comment on conceptual matters. Doing justice to such material may require considerable time. Because the survey response material is free flowing text, it requires a framework to structure the analysis, as was provided by the criterial framework in the case study presented here. The natural alternative might be to structure the survey further. However, that would detract from 
many of the strengths and would reduce the process to one more like a Delphi or similar convergent process and hence would be unsuitable for the task here engaged.

In the light of these considerations, the methodology here outlined and illustrated should be used thoughtfully and carefully. It may, though, be applied to concepts that are important in a given field, are not well conceptualised either through lack of research or consideration, and which would, if the methodology were undertaken, add significant value to the work of practitioners, researchers and teachers in the field.

\section{References}

Bacharach, S. B. (1989). Organizational theories: Some criteria for evaluation. The Academy of Management Review, 14(4), 496-515.

Blalock, H. M. (1969). Theory construction. NJ: Prentice-Hall.

Blalock, H. M. (1982). Conceptualization and measurement in the social sciences. Beverly Hills, CA: Sage.

Blumer, H. (1931). Science without concepts. American Journal of Sociology, 36(4), 515-533.

Blumer, H. (1954). What is wrong with social theory? American Sociological Review, 19(1), 310.

Carter, P. D. (2002). Building purposeful action: Action methods and action research. Educational Action Research, 10(2), 207-232.

Dubin, R. (1978). Theory building (Rev. ed.). New York, NY: Free Press.

Fawcett, J. (1995). Analysis and evaluation of conceptual models of nursing. Philadelphia, PA: F.A.Davis.

Gerring, J. (1999). What makes a concept good? A criterial framework for understanding concept formation in the social sciences. Polity, 31(3), 357-393.

Gerring, J. (2012). Social science methodology: A unified framework. Cambridge, U.K.: Cambridge University Press.

Glaser, B. G. (2002). Conceptualization: On theory and theorizing using grounded theory. International Journal of Qualitative methods, 1(2), 23-38.

Hatfield, L. A., \& Polomano, R. C. (2012). Infant distress: Moving toward concept clarity. Clinical Nursing Research, 21(2), 164-182. doi:10.1177/1054773811410601 
Heron, J., \& Reason, P. (2006). The practice of co-operative enquiry: Research with rather than on people. In P. Reason \& H. Bradbury (Eds.), Handbook of action research: The concise paperback edition (pp. 144-154). London: Sage,

Howie, P., \& Bagnall, R. (2015). The transmogrification of warm-up: From drama to psychodrama. The Arts in Psychotherapy, 44, 35-44.

Howie, P. C. (2012). Philosophy of life: J. L. Moreno's revolutionary philosophical underpinnings of psychodrama, and group psychotherapy. Group: The Journal of the Eastern Group Psychotherapy Society, 36(2), 135-146.

Kezar, A., \& Maxey, D. (2014). The Delphi technique: an untapped approach of participatory research. International Journal of Social Research Methodology, (ahead-of-print), 118.

Kuhn, T. S. (1977). The essential tension: Selected studies in scientific tradition and change. Chicago: University of Chicago Press.

Locke, E. A. (2012). Construct validity vs. concept validity. Human Resource Management, 22(2), 146-148. doi:10.1016/j.hrmr.2011.11.008

Meleis, A. I. (2012). Theoretical nursing: Development and progress. Philadelphia, PA: Wolters Kluwer Health/Lippincott Williams \& Wilkins.

Patterson, C. H. (1986). Theories of counseling and psychotherapy. New York: Harper \& Row.

Penwarden, R. (2014). Response rate statistics for online surveys - What numbers should you be aiming for?, Retrieved from http://fluidsurveys.com/university/responserate-statistics-online-surveys-aiming/

Prochaska, J. O., Wright, J. A., \& Velicer, W. F. (2008). Evaluating theories of health behavior change: A hierarchy of criteria applied to the transtheoretical model. Applied Psychology An International Review, 57(4), 561-561. doi:10.1111/j.14640597.2008.00345.x

Proctor, R. W., \& Capaldi, E. J. (2006). Why science matters: Understanding the methods of psychological research. Oxford: Blackwell.

Salmon, W. C. (1984). Logic ( $3^{\text {rd }}$ ed.). Englewood Cliffs, NJ: Prentice Hall.

Sartori, G. (1984). Guidelines for concept analysis. In G. Sartori (Ed.), Social science concepts: A systematic analysis. Beverly Hills, CA: Sage. 
Shelton, K., \& Creghan, K. A. (2014). Demystifying the Delphi method. In V. C. X. Wang (Ed.) Handbook of research on scholarly publishing and research methods (pp. 375-395). Hersey, PA: Information Science Reference.

Skulmoski, G., Hartman, F., \& Krahn, J. (2007). The Delphi method for graduate research. Journal of Information Technology Education: Research, 6(1), 1-21.

Wilson, J. (1969). Thinking with concepts. Cambridge, England: Cambridge University Press. 